\title{
Avaliação sobre a disposição irregular dos resíduos sólidos urbanos a partir de técnicas de sensoriamento remoto
}

O presente trabalho busca georreferenciar os pontos de disposição irregular de resíduos sólidos no entorno do riacho dos Macacos tomando como ponto inicial o Parque Ecológico das Timbaúbas, localizado em Juazeiro do Norte, sul do Ceará. Para a etapa de georreferenciamento foram realizadas visitas in loco percorrendo o riacho dos Macacos, no trecho entre o Parque Ecológico das Timbaúbas e o bairro Vila Fátima. A sustentabilidade do Parque é vital para o município, pelo fato de nele existir, a Lagoa dos Macacos, principal fonte de abastecimento do riacho e consequentemente do sistema de abastecimento de água municipal. Soluções técnicas isoladas, tais como coleta, tratamento e destinação final, vêm resolvendo parcialmente o problema, já que na medida em que o tempo decorre, observase que a quantidade e a complexidade dos resíduos vêm crescendo transformando-se em grave ameaça ao meio ambiente. Nesses aspectos, considera-se necessária a formulação de uma Lei Municipal voltada para gestão dos RSU, considerando as peculiaridades do local, cultura e educação da população, uma vez que o riacho dos Macacos é um dos principais afluentes do Rio Salgado. Além da implantação de projeto de revitalização do riacho das Timbaúbas e Riacho dos Macacos, uma vez que interferem diretamente na saúde e consequentemente na qualidade de vida da população.

\section{Evaluation of the irregular disposition of municipal solid waste from remote sensing techniques}

\begin{abstract}
The present work seeks to georeference the points of irregular disposal of solid waste in the surroundings of the Monkey Creek starting with the Timbaúbas Ecological Park, located in Juazeiro do Norte, south of Ceará. For the georeferencing stage, on-site visits were made through the Macacos stream, between the Parque Ecológico das Timbaúbas and the Vila Fátima neighborhood. The sustainability of the Park is vital for the municipality, because it exists in it, the Lagoa dos Macacos, the main source of supply of the stream and consequently of the municipal water supply system. Isolated technical solutions, such as collection, treatment and final disposal, have partially solved the problem, since as time goes on, it is observed that the quantity and complexity of the waste has been growing, becoming a serious threat to the environment environment. In these aspects, it is considered necessary to formulate a Municipal Law aimed at MSW management, considering the peculiarities of local population, culture and education, since the Monkey Creek is one of the main tributaries of the Salgado River. In addition to the implementation of a project to revitalize the Timbaúbas and Riacho dos Macacos rivers, since they directly interfere with health and consequently the quality of life of the population.
\end{abstract}

Keywords: Georeferencing; Riacho dos Macacos; Urban solid waste.

Topic: Geodésia, Cartografia e Sensoriamento Remoto

Reviewed anonymously in the process of blind peer.
Received: $12 / 01 / 2018$

Approved: 24/04/2018
Cicera Camila Alves Macêdo

Universidade Federal do Cariri, Brasil

http://lattes.cnpq.br/0579680993809474

calvesmacedo@gmail.com

Jair Paulino de Sales

Universidade Federal do Cariri, Brasil

http://lattes.cnpq.br/7099203116962634

jairpsales@hotmail.com

Sheilla da Silva Melo Figueirêdo

Universidade Federal do Cariri, Brasil

http://lattes.cnpq.br/5511200899904144

sheillamel@hotmail.com
Thaís Lucena Grangeiro

Universidade Federal do Cariri, Brasil

http://lattes.cnpq.br/0142299408136687

thaisjua@hotmail.com

Carlos Wagner Oliveira

Universidade Federal do Cariri, Brasil

http://lattes.cnpq.br/1699471147104107

carlos.oliveira@ufca.edu.br
Referencing this:

MACÊDO, C. C. A.; SALES, J. P.; FIGUEIRÊDO, S. S. M.; GRANGEIRO, T. L.; OLIVEIRA, C. W.. Avaliação sobre a disposição irregular dos resíduos sólidos urbanos a partir de técnicas de sensoriamento remoto. Nature and Conservation, v.11, n.1, p.1-8, 2018. DOI: http://doi.org/10.6008/CBPC2318-2881.2018.001.0001 


\section{INTRODUÇÃO}

O advento da globalização influenciou profundamente o modo de vida adotado pela população, principalmente no consumo de bens não duráveis e, portanto, na geração de resíduos sólidos. Neste sentido compreende-se a falta de educação e consciência ambiental da população como fatores contributivos para o agravamento de tais problemas (MACEDO et al., 2015).

A atual conjuntura econômica, política e social não deve se dissociar do 'pensar ambiental', defendido por Medina et al. (2003), como aquele oriundo de reflexões prospectivas e complexas, que deve incorporar formas inovadoras de idealizar o mundo globalizado, a natureza e a sociedade. Na ausência deste 'pensar ambiental' o problema com a geração e disposição de resíduos sólidos não consegue ser integrada à dinâmica do crescimento urbano, e passa a infligir danos à saúde pública em decorrência da presença de substâncias perigosas e infectantes em sua composição (PRÜSS-ÜSTÜN et al., 2006).

A maior parte dos resíduos sólidos urbanos (RSU) gerados é lançada em lixões, local caracterizado por receber a descarga diretamente no solo, sem medidas de proteção e a céu aberto. Descartes clandestinos de resíduo industrial constituem uma bomba de efeito retardado. Conforme Cafure et al. (2014):

Os impactos ambientais causados pelo gerenciamento inadequado dos resíduos hospitalares podem atingir grandes proporções, levando a contaminações e elevados índices de infecção hospitalar, ou até mesmo à geração de epidemias devido a contaminações do lençol freático pelos diversos tipos de resíduos dos serviços de saúde.

Um dos desafios do homem contemporâneo, portanto, é o de buscar formas de viver que permitam o equilíbrio entre o meio ambiente, suas necessidades econômicas e o bem-estar social. Caminhar em direção a uma gestão dos resíduos sólidos na busca pela eliminação de seus impactos negativos no ambiente e na saúde da população compreende a busca pelo desenvolvimento sustentável.

O presente trabalho busca georreferenciar os pontos de disposição irregular de resíduos sólidos no entorno do riacho dos Macacos tomando como ponto inicial o Parque Ecológico das Timbaúbas, localizado em Juazeiro do Norte, sul do Ceará. Analisar-se-á a disposição incorreta de resíduos no curso do riacho e seu impacto socioambiental a partir do que dispõe a Política Nacional de Resíduos Sólidos (Lei № 12.305/2010).

\section{REVISÃO TÉORICA}

\section{Política Nacional de Resíduos Sólidos}

A cidade é o espaço em que se consubstancia as relações humanas resultantes de fatores históricos, econômicos, sociais, culturais, geográficos e jurídicas, mas em seu território estão todas as desigualdades socioeconômicas do sistema econômico capitalista (PETHECHUST et al., 2016). A Constituição da República Federativa do Brasil de 1988, resguarda a todos os cidadãos e impõe ao poder público e à coletividade o dever de defender e preservar o meio ambiente ecologicamente equilibrado para as presentes e futuras gerações (BRASIL, 1988).

O lixo gerado pelas cidades, juridicamente nomeado como resíduos sólidos e rejeitos é um dos grandes empecilhos ao desenvolvimento socioambiental das cidades e compromete a efetivação do meio 
ambiente equilibrado, afetando a qualidade de vida do cidadão (PETHECHUST et al., 2016). Um dos problemas enfrentados no Brasil é a degradação ambiental causada pelo aumento populacional e consumo desenfreado nas cidades. De acordo com Bernardes (2013) "dentro da perspectiva da degradação ambiental das cidades, um dos pontos mais relevantes tem sido a geração de resíduos sólidos urbanos, e, mais especificamente, os Resíduos Sólidos Domésticos".

Dentro desta perspectiva de mudança dos hábitos de consumo percebe-se que são inúmeros fatores sociais que contribuem para o aumento dos RSU: falta de educação e conscientização ambiental da população, ocupação de solo urbano desenfreada, inadequadas infraestruturas sociais, dificuldade de acesso aos pontos de coleta seletiva e serviço de coleta ineficaz. Além disso, existe neste processo inúmeras falhas da gestão pública municipal em proporcionar à população um maior entendimento e conscientização sobre a importância do melhor tratamento e destinação desses resíduos.

Diante desta realidade, torna-se mais que necessário, verificar a lei $n^{\circ} 12.305$ de 02 de agosto de 2010 que complementa as legislações que protegem o direito à cidade, e através dos mecanismos jurídicos institui a Política Nacional de Resíduos Sólidos (PNRS). 0 artigo $6^{\circ}$ da referida lei, dispõe sobre alguns princípios: prevenção e a precaução; poluidor-pagador e o protetor-recebedor; visão sistêmica, gestão dos resíduos sólidos, que considere as variáveis ambiental, social, cultural, econômica, tecnológica e de saúde pública; desenvolvimento sustentável; ecoeficiência; cooperação entre as diferentes esferas do poder público, o setor empresarial e demais segmentos da sociedade; o reconhecimento do resíduo sólido reutilizável e reciclável como um bem econômico e de valor social, gerador de trabalho e renda e promotor de cidadania, entre outros (BRASIL, 2010).

Dentro desta perspectiva legislativa, cabe destaque a visão sistêmica para a gestão destes resíduos que envolve as variáveis ambientais, sociais, culturais, econômicas, tecnológica e de saúde pública. Além disso, a PNRS propõe a cooperação entre as diferentes esferas do poder público, um mínimo consumo de recursos naturais para a redução do impacto ambiental, responsabilidade pelo ciclo dos produtos e o direito à informação. Para tanto, torna-se necessário a mudança da perspectiva dos resíduos sólidos pelos consumidores para que compreenda os produtos não apenas como 'lixo', ou seja, algo descartável sem valor econômico, mas como um bem reutilizável e reciclável com amplo valor social. Torna-se necessária a responsabilização pelo lixo gerado nas cidades a partir do entendimento de que os RSU poderão gerar renda aquela localidade e propor cidadania.

Esta Lei ainda determina que os municípios, microrregiões e regiões metropolitanas instituam um plano de resíduos sólidos e cria o Sistema Nacional de Informações sobre a Gestão de Resíduos Sólidos. Com os seguintes objetivos (artigo $7^{\circ}$ ):

I - proteção da saúde pública e da qualidade ambiental;

II - não geração, redução, reutilização, reciclagem e tratamento dos resíduos sólidos, bem como disposição final ambientalmente adequada dos rejeitos;

VII - gestão integrada de resíduos sólidos; 
VIII - articulação entre as diferentes esferas do poder público, e destas com o setor empresarial, com vistas à cooperação técnica e financeira para a gestão integrada de resíduos sólidos;

XII - integração dos catadores de materiais reutilizáveis e recicláveis nas ações que envolvam a responsabilidade compartilhada pelo ciclo de vida dos produtos.

Percebe-se que os problemas dos RSU são complexos já que envolve o modelo econômico de mercado na sociedade de consumo, necessitando de uma gestão integrada com a articulação entre as diferentes esferas do poder público para tratar desde a não geração destes resíduos até a disposição final adequada dos dejetos. Mesmo com esse panorama, a cidade de Juazeiro do Norte ainda não possui um plano integrado como estipula a PNRS tendo a maior parte dos RSU depositados em lixões.

\section{METODOLOGIA}

Estudo de natureza aplicada com objetivos exploratório-descritivos de abordagem quanti-qualitativa que utilizou como procedimentos pesquisas bibliográficas e o estudo de caso (GIL, 2010). Salienta-se que estudos exploratório-descritivos objetivam a descrição detalhada do fenômeno analisado, de forma a aproximar o pesquisador do corpus da pesquisa a partir de ferramentas de observação e descrição (MARCONI et al., 2017). Já Yin (2015) define estudo de caso como uma pesquisa empírica que analisa um fenômeno a partir da realidade, sobretudo quando não há fronteiras bem definidas entre o contexto real e o objeto de estudo.

\section{Caracterização da área de estudo}

O estudo foi realizado entre os meses de maio e julho de 2017, no município de Juazeiro do Norte, Região Metropolitana do Cariri, sul do Ceará, a 514 km da capital Fortaleza (Figura 01). O município possui área equivalente a $248.558 \mathrm{~km}^{2}$, uma altitude média de $377,3 \mathrm{~m}$ em relação ao nível do mar, com longitude 39o 18' 55" e latitude 07ㅇ 12' 47"' (CUNHA et al., 2016).

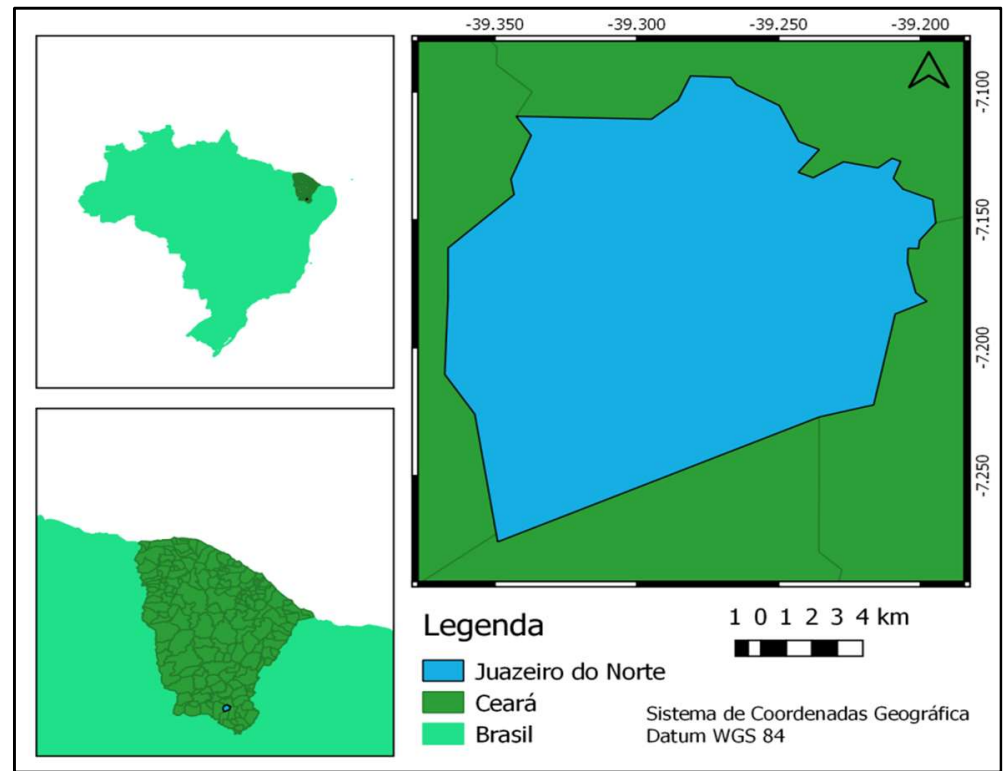

Figura 1: Localização da área de estudo, município de Juazeiro do Norte (CE). 


\section{Materiais e método}

Para a etapa de georreferenciamento foram realizadas visitas in loco percorrendo o riacho dos Macacos, no trecho entre o Parque Ecológico das Timbaúbas e o bairro Vila Fátima. O referido parque detém a Lagoa dos Macacos, principal fonte de abastecimento do riacho e consequentemente do sistema municipal (FRANCA et al., 2006; OLIVEIRA, 2014). Escolheu-se este percurso considerando que o entorno do Riacho dos Macacos encontra-se visualmente contaminado por esgotos domésticos e pela presença de RSU em suas margens. Utilizou-se um GPS Garmin eTrex e as coordenadas foram tratadas com auxílio do software QGIS 2.14 .

\section{RESULTADOS E DISCUSSÃO}

Nas visitas foi possível perceber o acúmulo irregular de RSU de origem doméstica e industrial ao longo do Riacho dos Macacos e do Parque Ecológico das Timbaúbas, conforme mostrado na Figura 2. Foram georreferenciados 11 pontos, entre os quais se percebe uma grande variabilidade do tipo de resíduos. 0 Riacho dos Macacos é um dos afluentes do rio Salgado, o mesmo corta o munícipio de Juazeiro do Norte e é um dos principais contribuintes do abastecimento hídrico da cidade, além de compor o cenário paisagístico no interior do Parque Ecológico das Timbaúbas, o qual conta com a presença de duas lagoas (MACÊDO et al., 2014).

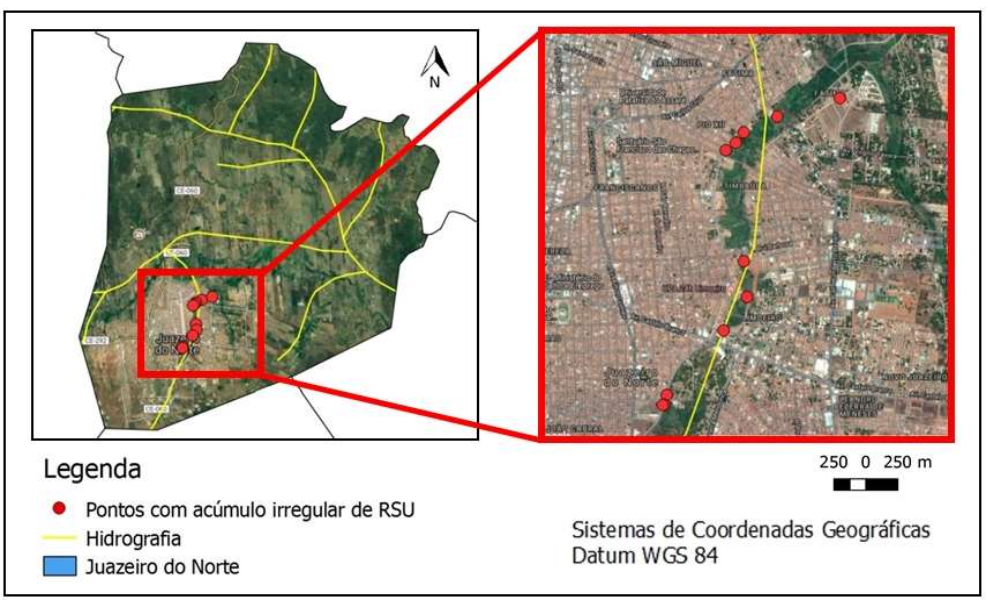

Figura 2: Pontos com acúmulo irregular de RSU no município de Juazeiro do Norte.

Na região da Chapada do Araripe, área do estudo, a alta permeabilidade das rochas sedimentares limita o escoamento superficial e favorece a alimentação dos aquíferos, compensando a escassez ou ausência de rios pelo maior potencial de águas subterrâneas. No entanto, de acordo IPECE, a cidade de Juazeiro do Norte conta com apenas 36,13\% de cobertura de rede de coletora de esgoto, fato que impulsiona a população a utilizar sistemas individuais de disposição de efluentes, como fossas e tanques sépticos.

Referindo-se ao Riacho dos Macacos, estudos realizados demostram interações entre as águas superfícies poluídas com as águas subterrâneas, sobretudo onde estão inseridos poços de captação na região (SANTOS, 2004; FRANCA et al., 2006). Análises mais recentes apontam correlação entre as concentrações de $\mathrm{N}-\mathrm{NO}^{3-}$ e $\mathrm{Cl}^{-}$, provenientes de esgoto doméstico, e a vulnerabilidade da área (ALMEIDA, 2015). 
O lançamento de esgotos in natura aliado à disposição irregular dos resíduos sólidos ocasiona sérios danos à saúde da população e ao meio ambiente. Zara et al. (2016), afirma que a gestão dos RSU possui estreita ligação com os índices de saúde pública, destacando os problemas oriundos da proliferação de mosquitos, em especial o Aedes aegypti, como os surtos de Dengue, Zika e Chikungunya e Febre Amarela no Brasil. Há de se salientar que a disposição incorreta de RSU é um fenômeno que se percebe quase que exclusivamente em áreas subdesenvolvidas, longe dos bairros nobres das cidades, como deixa claro Lesser et al. (2016) quando escrevem sobre a "geográfica social do zika no Brasil".

A universalização do serviço de coleta regular de resíduos sólidos domiciliares torna-se então necessária, visando a contribuir para a redução do quadro de morbimortalidade das crianças residentes em áreas carentes deste importante serviço de saneamento ambiental. Importância também deve ser dada à educação sanitária e ambiental visando à sua contribuição para o processo de mudança de atitudes e práticas das pessoas quanto ao manejo e acondicionamento domiciliar dos resíduos sólidos (MORAES, 2007).

As Figuras 3 e 4 mostram a realidade da falta de gestão ambiental e aplicabilidade de política municipal de Juazeiro do Norte/CE, no que tange os resíduos sólidos, sendo encontrados, na área de estudo, equipamentos eletrônicos, materiais da construção civil, papel, plástico, resíduos orgânicos, borrachas de processos produtivos do setor calçadista (quadro 1).
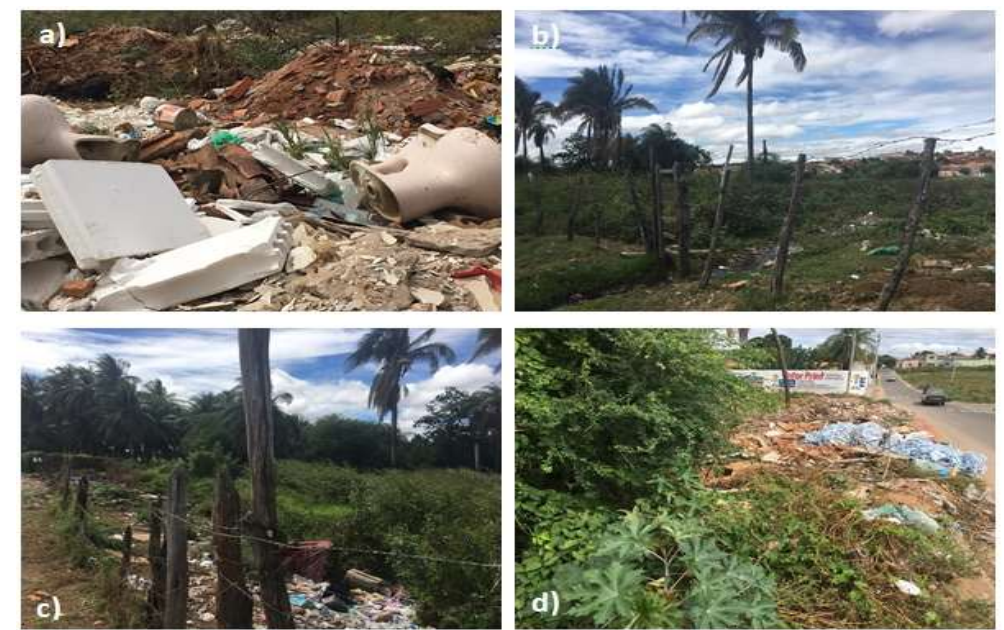

Figura 3: Acúmulo irregular de RSU no município de Juazeiro do Norte-CE.
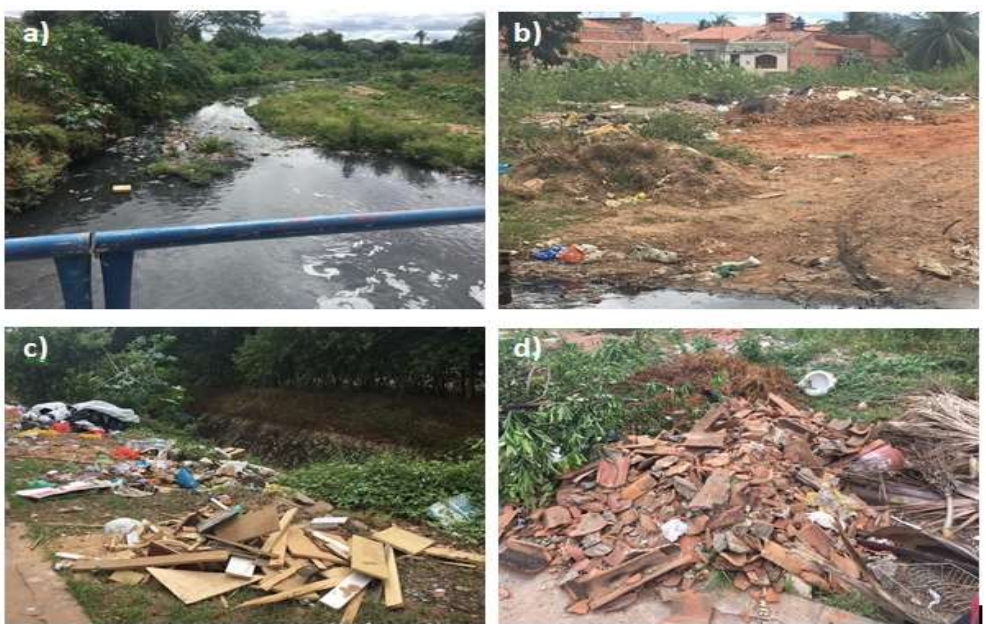

Figura 4: Acúmulos irregulares de RSU no município de Juazeiro do Norte-CE. 
Quadro 1: Resíduos sólidos encontrados na área de estudo.

\begin{tabular}{|l|l|}
\hline RSU (CATEGORIA) & RSU ENCONTRADOS \\
\hline Orgânicos & Restos alimentares, podas de árvores. \\
\hline Plásticos & $\begin{array}{l}\text { Sacos; sacolas; embalagens de refrigerantes, água e leite; embalagens de produtos de limpeza; } \\
\text { produtos de beleza, cartela de kit de joias (bolhas). }\end{array}$ \\
\hline Vidro & Garrafas de bebidas, vidros de alimentos no geral e lâmpadas. \\
\hline Madeira & Móveis no geral (sofás, cadeiras, restos de cama, armário), restos de podas de árvores. \\
\hline Tecidos e borrachas & Roupas, sapatos, pneus de automóveis, borracha industrial do setor calçadista. \\
\hline Construção Civil & Pregos, entulhos (areia, cerâmica, tijolos, telhas), gesso, vasos sanitários. \\
\hline Contaminante químico & Papel higiênico, fraldas descartáveis. \\
\hline $\begin{array}{l}\text { Equipamento eletrônico } \\
\text { Eletrodoméstico }\end{array}$ & Televisão, rádio, liquidificador. \\
\hline
\end{tabular}

Conforme Kraemaer (2014, citado por ARAÚJO et al., 2016):

Somos a sociedade dos resíduos, porém, só acordamos recentemente para esta realidade; nos últimos 20 anos a população mundial cresceu menos que o volume de resíduos por ela produzido. Enquanto de 1970 a 1990 a população do planeta aumentou em 18\%, a quantidade de resíduos sobre a Terra passou a ser $25 \%$.

No Brasil 58\% do total dos resíduos gerados são descartados em locais inadequados (ABRAPEL, 2012). E de acordo Araújo et al. (2016), o acondicionamento e descarte inadequado dos RSU podem causar diversos problemas socioambientais, sendo por meio da proliferação de vetores (saúde), ao meio ambiente em si (água, ar e solo), como também para a estética local. Com isso, Leite (2006) destaca que se faz necessário estabelecer relação de harmonia e não de domínio da natureza. Sendo essa uma das formas de contribuição para conservação ambiental.

\section{CONCLUSÕES}

O presente artigo teve por objetivo avaliar a contaminação dos Resíduos Sólidos Urbanos nas margens e entorno do Riacho dos Macacos, no município de Juazeiro do Norte/CE, utilizando assim para coleta dos dados, o GPS Garmin eTrex e registros fotográficos. Diante do estudo, foram encontrados acúmulos irregulares de resíduos sólidos urbanos domésticos e de origem industrial ao longo do Riacho dos Macacos, tais como: restos alimentares, podas de árvores, Plásticos, sacolas, embalagens de refrigerantes, embalagens de produtos de limpeza, garrafas de bebidas, vidros de alimentos no geral, lâmpadas, madeiras de móveis no geral, restos de podas de árvores, tecidos, borrachas, roupas, sapatos, pneus de automóveis, borracha industrial do setor calçadista, pregos, entulhos, gesso, vasos sanitários, contaminantes químicos em geral, entre outros.

Nesses aspectos, considera-se necessária a formulação de uma Lei Municipal voltada para gestão dos RSU, considerando as peculiaridades do local, cultura e educação da população, uma vez que o riacho dos Macacos é um dos principais afluentes do Rio Salgado. Além da implantação de projeto de revitalização do riacho das Timbaúbas e Riacho dos Macacos, uma vez que interferem diretamente na saúde e, consequentemente, na qualidade de vida da população.

\section{REFERÊNCIAS}


riacho dos macacos em Juazeiro do Norte/Ceará. Tese (Doutorado em Engenharia Civil) - Universidade Federal do Ceará, Fortaleza, 2015.

ARAÚJO, K. K.; PIMENTEL, A. K.. A problemática do descarte irregular dos resíduos sólidos urbanos nos bairros Vergel do Lago e Jatiúca em Maceió, Alagoas. Revista de gestão e sustentabilidade ambiental, v.4, n.2, p.626-668, 2016.

BERNARDES, M. S.. Os desafios para efetivação da Política Nacional de Resíduos Sólidos frente a figura do consumidorgerador. Revista Eletrônica do Curso de Direito da UFSM, v.8, n.1, p.196-207, 2013.

BRASIL. Constituição da República Federativa do Brasil de 1988. Brasília: Centro Gráfico, 1988.

CAFURE, V. A.; GRACIOLLI, S. R. P.. Os resíduos de serviço de saúde e seus impactos ambientais: uma revisão bibliográfica. Interações, v.16, n.2, p.301-314, 2015.

CUNHA, M. A.; LISBOA, T. E. S. D.; SILVA, R. F.. Examinando questões do livro didático e da prática docente na geografia escolar do Ensino Médio: levantamento empírico realizado em Juazeiro do Norte/CE. Geosertões, v.1, n.1, p.90-100, 2016.

FRANCA, R. M.; FRISCHKORN, H.; SANTOS, M. R. P.; MENDONÇA, L. A. R.; BESERRA, M. C.. Contaminação de Poços Tubulares em Juazeiro do Norte/CE. Revista de Engenharia Sanitária e Ambiental, v.11, n.1, p.92-102, 2006.

GIL, A. C.. Como elaborar projetos de pesquisa. 5 ed. São Paulo: Atlas, 2010.

LEITE, M. F.. A taxa de coleta de resíduos sólidos domiciliares uma análise crítica. São Carlos, 2006.

LESSER, J.; KITRON, U.. A geografia social do zika no Brasil. Estud. av., v.30, n.88, p.167-175, 2016.
MACEDO, M. A. P. T.; RAMOS, M. C. P.. Educação Ambiental e Resíduos Sólidos Urbanos: Caminho para um Futuro Sustentável. Eduser, v.7, n.2, p.41-57, 2015.

MARCONI, M. A.; LAKATOS, E. M.. Fundamentos de metodologia científica. 8 ed. São Paulo: Atlas, 2017.

MEDINA, N. M.; SANTOS, E. C.. Educação Ambiental: uma metodologia participativa de formação. 3 ed. Petrópolis: Vozes, 2003

MORAES, L. R. S.. Acondicionamento e coleta de resíduos sólidos domiciliares e impactos na saúde de crianças residentes em assentamentos periurbanos de Salvador/BA. Cad. Saúde Pública, v.23, n.4, p.643-S649, 2007.

OLIVEIRA, J. L.. Avaliação de indicadores de poluição de solos e águas e suas implicações no sistema de abastecimento público de Juazeiro do Norte-CE. Dissertação (Mestrado em Engenharia Civil) - Universidade Federal do Ceará, Fortaleza, 2014.

PETHECHUST, E. R. B.; CASIMIRO, L. M. S. M.. O direito à cidade: eficiência da política nacional de resíduos sólidos à luz da análise econômica do direito. Revista de Direito da Cidade, v.8, n.1, p.294-307, 2016.

PRÜSS-ÜSTÜN, A.; CORVALÁN, C.. Preventing disease through healthy environments: Towards an estimate of the environmental burden of disease. Geneva: World Health Organization, 2006.

SANTOS, M. R. P.. Transporte Advectivo de Poluentes do Riacho dos Macacos ao Aquífero Rio da Batateira na Cidade de Juazeiro do Norte/CE. Monografia (Bacharelado em Física) - Universidade Federal do Ceará, Fortaleza, 2004.

YIN, R. K.. Estudo de Caso: Planejamento e Métodos. 5 ed. Porto Alegre: Bookman, 2015.

ZARA, A. L. S. A.. Estratégias de controle do Aedes aegypti uma revisão. Epidemiol. Serv. Saúde, v.25 n.2, p.391-404, 2016.

A CBPC - Companhia Brasileira de Produção Científica (CNPJ: 11.221.422/0001-03) detém os direitos materiais desta publicação. Os direitos referem-se à publicação do trabalho em qualquer parte do mundo, incluindo os direitos às renovações, expansões e disseminações da contribuição, bem como outros direitos subsidiários. Todos os trabalhos publicados eletronicamente poderão posteriormente ser publicados em coletâneas impressas sob coordenação da Sustenere Publishing, da Companhia Brasileira de Produção Científica e seus parceiros autorizados. Os (as) autores (as) preservam os direitos autorais, mas não têm permissão para a publicação da contribuição em outro meio, impresso ou digital, em português ou em tradução. 